\title{
Sociedade Brasileira de Atividade Física e Saúde: Gestão 2012/2013
}

Pedro C Hallal ${ }^{1}$

Rev Bras Ativ Fis Saúde p. 397-398 DOI:

http://dx.doi.org/10.12820/rbafs.v.18n4p397

1 Presidente da SBAFS 2012/2013
Foi com satisfação que recebi o convite dos editores científicos da Revista Brasileira de Atividade Física e Saúde (RBAFS) para fazer uma análise da gestão que se encerra no final do ano de 2013. Prestar contas é responsabilidade de qualquer pessoa que ocupe cargos representativos.

A Sociedade Brasileira de Atividade Física e Saúde (SBAFS) completa seu sexto ano e terceiro ciclo diretivo. Ao longo das primeiras gestões anos, foi possível consolidar o Congresso Brasileiro de Atividade Física e Saúde (CBAFS) e alavancar a RBAFS, os dois carros chefe da SBAFS. A terceira gestão, iniciada em 2012, deveria então enfrentar os novos desafios da área, visto que os carros chefe já estavam no piloto automático.

Uma das metas estabelecidas foi investir em recursos humanos, priorizando a formação de pesquisadores na área de atividade física e saúde. A principal ação criada para atingir esse objetivo foi a organização do primeiro Curso de Atividade Física e Saúde Pública, um evento de pequeno porte com características de imersão. O evento foi realizado na cidade de Curitiba no ano de 2013 e superou todas as nossas expectativas. Desde o processo seletivo até a avaliação do produto, notamos o quanto estávamos certos em investir na formação de pessoas, as quais agora são responsáveis por multiplicarem os ensinamentos adquiridos. A ideia é que o curso mantenha frequência anual, um desafio para a próxima gestão da SBAFS.

Outra meta estabelecida foi aumentar a captação de associados. Tal objetivo foi apenas parcialmente atingido, visto que mesmo com o grande aumento do número de associados, ainda estamos muito abaixo do potencial da área. Se pensarmos que o CBAFS atrai pelo menos 800 pessoas a cada dois anos e que praticamente todos os cursos de graduação e pós-graduação da Educação Física no Brasil possuem conteúdos relacionados à atividade física e saúde, é fundamental que a SBAFS congregue em seu quadro de associados centenas de profissionais e estudantes, os quais, juntos, definirão os rumos que a área deve tomar.

Uma meta que não foi atingida foi a publicação de posicionamentos oficiais sobre temas polêmicos da área. A SBAFS não pode ficar de fora das discussões sobre a formação em Educação Física, a inserção do profissional de Educação Física no Sistema Único de Saúde, os limites profissionais na prescrição de exercícios físicos e vários outros tópicos que permeiam o dia a dia da área. Fica o desafio para a próxima gestão de avançar nesse quesito.

A busca incessante por uma área de Educação Física e Esportes mais unida foi outra prioridade da SBAFS. Ao longo dos últimos anos, a Educação Física tem se dividido em "gavetas" isoladas, com pouca comunicação entre si. Embora isso teoricamente favoreça o desenvolvimento independente das subáreas da profissão, na prática gera um enfraquecimento da área como um todo, visto que nenhuma das subáreas fica responsável por pensar os rumos da Educação Física. É fundamental que as diversas sociedades científicas da área de Educação Física e Esportes sejam congregadas em alguma federação ou associação que represente a área como um todo. 
Da mesma forma, é evidente um distanciamento entre a pesquisa desenvolvida em Educação Física e a realidade profissional. Precisamos fazer com que a pesquisa desenvolvida na área chegue àqueles que atuam na escola, no esporte, na saúde, nas academias e nos outros espaços profissionais de atuação da área. A criação de mestrados profissionais pode ser um caminho para avançar nesse sentido.

Talvez a maior conquista da gestão 2012-2013 da SBAFS tenha sido trazer para o Brasil o principal evento da área no mundo. O V International Congress of Physical Activity and Public Health (ICPAPH), antes realizado em Atlanta (EUA), Amsterdam (Holanda), Toronto (Canadá) e Sydney (Austrália), será sediado no Rio de Janeiro entre 08 e 11 de abril de 2014. É a hora de a SBAFS mostrar ao mundo o papel de liderança que o Brasil ocupa na área, já sinalizado na Série de Atividade Física publicada no Lancet em 2012.

Não poderia deixar de agradecer a cada um dos meus colegas de diretoria, que tornaram possíveis nossos avanços. Se dependesse desse grupo, teríamos alcançado todos os objetivos traçados lá em 2011. Por fim, é fundamental assumir publicamente a responsabilidade por cada uma das metas não atingidas. Espero que a área continue a crescer, não mais na progressão geométrica observada até hoje, mas sim numa progressão aritmética cadenciada, responsável e madura. 